\title{
A Comparative Assessment of the Antibacterial Activity in Fruit Juice of Sri Lankan Sweet Orange Cultivars vis a vis Sour Orange
}

\author{
H. M. P. D. Herath, M. D. M. Chamikara, D. R. R. P. Dissanayake, \\ M. D. M. I. M. Dissanayake, M. Ishan, S. Rajapakse and S. D. S. S. Sooriyapathirana ${ }^{1}$ \\ Received : 17 th July 2015 / Accepted : 06 ${ }^{\text {th }}$ November 2015
}

\begin{abstract}
Sweet orange (Citrus sinensis), a key fruit species, is considered as a primary ingredient in herbal medical formulations against ailments such as food borne diseases. Sour orange $(C$. aurantium) is also very famous as a medicinal plant. There are six commonly grown sweet orange cultivars in Sri Lanka (Arogya, Bibila sweet, MKD, Sisila, BAN and MT) but the antibacterial activity present in their fruit juice is not well documented. Therefore, the present study was conducted to characterize the antibacterial activity of the fruit juice of these sweet oranges in comparison to sour orange and also to establish DNA barcodes for the tested cultivars for precise identification. Fruit juice was collected from sweet orange cultivars and sour orange and antibacterial activity was measured against three model pathogenic bacterial species, Escherichia coli, Staphylococcus aureus and methicillin-resistant $S$. aureus. After employing filter paper disc method, the diameter of zone of bacterial inhibition (DZI) was measured as the parameter of antibacterial activity. The genomic DNA was extracted from all the tested plants and PCR amplified using trnH-psbA primer pair and subjected to DNA sequencing, followed by alignment analysis and dendrogram construction. Arogya and $M K D$ did not show any antibacterial activity (DZI $=0.0 \mathrm{~mm}$ ), whereas Sisila, BAN and $M T$ showed antibacterial activity only against $E$. coli and $S$. aureus (mean DZI of $8.2 \mathrm{~mm}$ and $8.4 \mathrm{~mm}$ respectively). Bibila sweet and sour orange showed significantly higher antibacterial activity against all E. coli, $S$. aureus and methicillin-resistant $S$. aureus (mean DZI of $10.2 \mathrm{~mm}$, $10.5 \mathrm{~mm}$ and $7.8 \mathrm{~mm}$ respectively). DNA barcoding provided unique sequence identifiers for each cultivar. These antibacterial activity data in combination with DNA barcodes could help to develop new cultivars through breeding to promote the sweet orange industry in Sri Lanka.
\end{abstract}

Keywords: Sweet orange, Sour orange, Citrus sinensis, Citrus aurantium, antibacterial activity, disc diffusion method, Citrus DNA barcoding

\section{INTRODUCTION}

Sweet orange, Citrus sinensis, is one of the delicious fruits consumed by human beings and it is industrially important as one of the major fruit crops. The global Citrus cultivations cover approximately nine billion hectares, leading to 122.3 million tonnes of fresh fruit harvest $(\mathrm{Xu}$ et al., 2013). In Sri Lanka sweet orange industry is not so developed but there is a huge demand for sweet oranges within the country. Because of the nutraceutical values and antioxidant activities (Abeysinghe et al., 2007), sweet orange is currently being consumed as a health promoting and disease preventing food (Okwu and Emenike, 2006). Citrus is a good source of natural bioactive compounds such as vitamin $C$, carotenoids (Xu et al., 2006), flavonoids (Okwu and Emenike, 2006), limnoids (Khalil et al., 2003), essential oils, acridone alkaloids (TianShung et al., 1983), minerals and vitamin B (Madhuri et al., 2014). Therefore, unlike in the 
past, there is a huge attention on sweet orange in the modern society as a food for better health.

There are six commonly grown sweet orange cultivars available in Sri Lanka. Their important fruit traits have been characterized and the cultivar recommendations were made for large scale planting (Herath et al., 2014). However, neither antibacterial activities of sweet orange cultivars nor the cultivar identities were established based on DNA sequences. In a large scale application of sweet orange, such as producing natural antibacterial herbal formulations, it is important to establish the identity of each sweet orange cultivar, because each cultivar is unique in its properties (Hearth et al., 2014; Youseif et al., 2014). The cultivar identity can be established using molecular methods such as DNA barcoding (Chase et al., 2005). DNA barcoding of plants is the sequencing of chloroplast or nuclear genome specific DNA loci such as the regions flanked by the primer pair trnH and $p s b A$ (Pang et al., 2012). DNA barcoding is frequently used to establish the genetic identity of many medicinally important species such as Chinese Bupleurum (Chao et al., 2014), Ginseng (Zuo et al., 2011), medicinal Labiatae plants in Chios Island (Theodoridis et al., 2012), medicinal vines (Liu et al., 2012) and medicinal orchids (Asahina et al., 2010).

Asian countries are famous for traditional medical practices such as Ayurveda, Unani, and Sidhdha. Citrus fruits are proven to possess numerous medical properties according to the ancient reports. The use of oranges in historical medical practices is also reported in India (Harborne, 1994), China (Zhou et al., 2013), Japan (Hirota et al., 2010) and Africa (Aibinu et al., 2007). Though it is not very clear that ancient people in Sri Lanka really used sweet orange or any other type of orange, the word 'orange' is very frequently indicated in historical reports on various medical practices (Fonseka, 1902). Plant extracts and phytochemicals with antimicrobial activity have been used as therapeutics since ancient times (Seenivasan et al., 2006). It has been reported that peel extracts of genus Citrus contain antibacterial activity on Escherichia coli, Proteus vulgaris, Bacillus subtilis, Klebsiella pneumoniae, Pseudomonas aeruginosa (Kabra et al., 2012), B. cereus (Madhuri et al., 2014) and Salmonella typhimurium (Dhanavade et al., 2011). Furthermore, there are reported antibacterial effects in Citrus fruit juices against E. coli, S. paratyphi, Shigella sonnei (Bansode and Chavan, 2012), Staphylococcus aureus, Proteus vulgaris and $P$. aeruginosa (Al-Ani et al., 2010). A species similar to $C$. sinensis known as $C$. aurantium, also known as sour orange because of its extreme sourness, is available in Sri Lanka. The sour orange is very popular in ayurvedic medical preparations than sweet orange. However, for fresh fruit consumption and industrial possessing of fruit juice, sour orange is not much used because of its higher acidity (Herath et al., 2014). Therefore it is important to study the medicinal values of sweet orange in comparison to sour orange.

Food borne diseases caused by bacteria is a huge problem in modern day food supplies. Most of the disease causing and food poisoning bacteria are becoming resistant to available antibiotics because of the prolonged and frequent exposure to them. The plant based antibacterial compounds would be ideal to combat this problem. If natural plant extracts have antibacterial activities they are useful in controlling the bacterial diseases. According to many historical reports, orange has often been used as a popular plant material in treating ailments related to digestive tract (Fonseka, 1902). This implies that in addition to the various other biochemical properties, orange juice must have antimicrobial activities. It is important to characterize the antibacterial activity of sweet and sour oranges against the commonly found model pathogenic strains, to have an idea on the impact of the numerous food borne pathogens naturally living. However, no studies have been conducted in this regard using Sri Lankan sweet orange cultivars and sour orange. Therefore, the 
present study was conducted to characterize the antibacterial activity of sweet and sour oranges in Sri Lanka against three model pathogenic strains and to assign DNA based identifiers to the tested cultivars using $\operatorname{trn} H-p s b A$ based DNA barcoding. This would enable the exact identification of these cultivars for large scale commercial applications in the future.

\section{MATERIALS AND METHODS}

\section{Assessment of the Antibacterial Activity}

\section{Sample Preparation}

The ripe fruits from six sweet orange cultivars (Arogya, Bibila sweet, MKD, Sisila, BAN and $M T$ ) and sour orange were collected from Regional Agricultural Research and Development Centers at Bandarawela and Monaragala, Sri Lanka. The juice was obtained from each fruit sample by pressing, using a household squeezer.

\section{Antibacterial Activity}

Assessment of antibacterial activity was conducted according to the completely randomized design (CRD) with three replicates. The disc diffusion method was used with three model pathogenic bacterial strains, E.coli (JM 109) and S. aureus (NCTC 4838) and Methicillin-resistant $S$. aureus (MRSA) for the detection of antibacterial activity of the juice samples. Mueller Hinton Agar (MHA) plates were prepared by pouring $20 \mathrm{ml}$ of autoclaved MHA to each plate. After that, $100 \mu$ l of bacterial cell cultures were spread separately on the medium. The autoclaved $6 \mathrm{~mm}$ Whatman filter paper discs were placed on the medium (Figure 01 ) and the plates were labeled properly to identify each sample separately. The discs were moistened with $30 \mu \mathrm{l}$ of the juice sample and the plates were incubated at $37^{\circ} \mathrm{C}$ for 12 hours. Distilled water was used as the control. Finally the diameter of the zone of inhibition (DZI) was measured. In addition to the antibacterial activity, the presence of four phytochemicals in fruit juice samples was also checked.

Tannins: A total of $2 \mathrm{ml}$ of each juice sample was taken, mixed with the same amount of distilled water, and heated at $100^{\circ} \mathrm{C}$ for $10 \mathrm{~min}$ $\mathrm{n}$ a water bath. A total of five drops of $1 \%$ ferric chloride was added and the colour change was observed.

Reducing Sugar: A total of $2 \mathrm{ml}$ juice sample was boiled with same amount of Benedict's solution for $10 \mathrm{~min}$ at $100^{\circ} \mathrm{C}$. Then the colour change was observed.

Flavonoids: A total of $0.2 \mathrm{ml}$ juice sample was added to $0.2 \mathrm{ml}$ of $\mathrm{NaOH}$. Then 1-2 drops of $\mathrm{HCl}$ was added to the solution. Finally the colour change was observed.

Phlobatannins: A total of $0.1 \mathrm{ml}$ of $\mathrm{HCl}$ was added to $2 \mathrm{ml}$ of juice sample. The sample was boiled in a water bath for $10 \mathrm{~min}$. Finally the colour change was observed.

\section{DNA Barcoding}

Genomic DNA were extracted from young leaf samples of six sweet orange cultivars and sour orange using Dneasy ${ }^{\circledR}$ plant mini kit (QIAGEN, Solna, Sweden). PCR amplification was carried out with trnH-psbA primer pair (Pang et al., 2012) using a thermal cycler (Takara, Japan) with initial denaturation at $94{ }^{\circ} \mathrm{C}$ for $5 \mathrm{~min}$; 35 cycles of denaturation at $94{ }^{\circ} \mathrm{C}$ for $30 \mathrm{sec}$, annealing at $57{ }^{\circ} \mathrm{C}$ for $1.5 \mathrm{~min}$, extension at 72 ${ }^{0} \mathrm{C}$ for $2.5 \mathrm{~min}$ and final extension at $72{ }^{\circ} \mathrm{C}$ for 10 min. A $15 \mu 1$ PCR mixture was prepared containing $1 \times$ Gotaq $^{\circledR}$ Green Master Mix (Promega Corperation, Madison, Wisconsin, USA), $0.5 \mu \mathrm{M}$ each of forward and reverse primers and $1.5 \mu \mathrm{l}$ of DNA template. The PCR products were sequenced using Sanger Sequencing based ABI 3500 Series Genetic Analyzer (Applied Biosystems ${ }^{\circledR}$ ).

\section{Data Analysis}

The antibacterial data were analyzed using 
ANOVA procedure in the statistical package SAS 9.13 (SAS Institute, Cary, NC, USA). The DNA sequence alignment analysis was carried out and a dendogram was constructed using the multiple sequence alignment package Clustal Omega (http://www.ebi.ac.uk).

\section{RESULTS}

\section{Antibacterial Activity}

The sweet orange cultivars, Arogya and $M K D$ did not exhibit any antibacterial activity and no inhibition zone was observed in the control (Figure 01). Sour orange demonstrated the highest antibacterial activity with $10.8 \mathrm{~mm}$ of mean DIZ against E. coli and S. aureus and 9.3 mm of mean DZI against MRSA. The sweet orange cultivar Bibila sweet also exhibited significantly higher activity against $E$. coli, $S$. aures and MRSA $(9.5 \mathrm{~mm}, 10.2 \mathrm{~mm}$ and 6.3 $\mathrm{mm}$ respectively). Bibila sweet and sour orange exhibited more or less similar antibacterial activities. The sweet orange cultivar Sisila, $B A N$ and $M T$ showed significantly higher antibacterial activity against $E$. coli and $S$. aureus but they had no activity against MRSA (Table 01).

\section{Phytochemicals}

The studied phytochemicals tannins, reducing sugar, flavonoids and phlobatannins were present in all the studied sweet orange cultivars and sour orange.
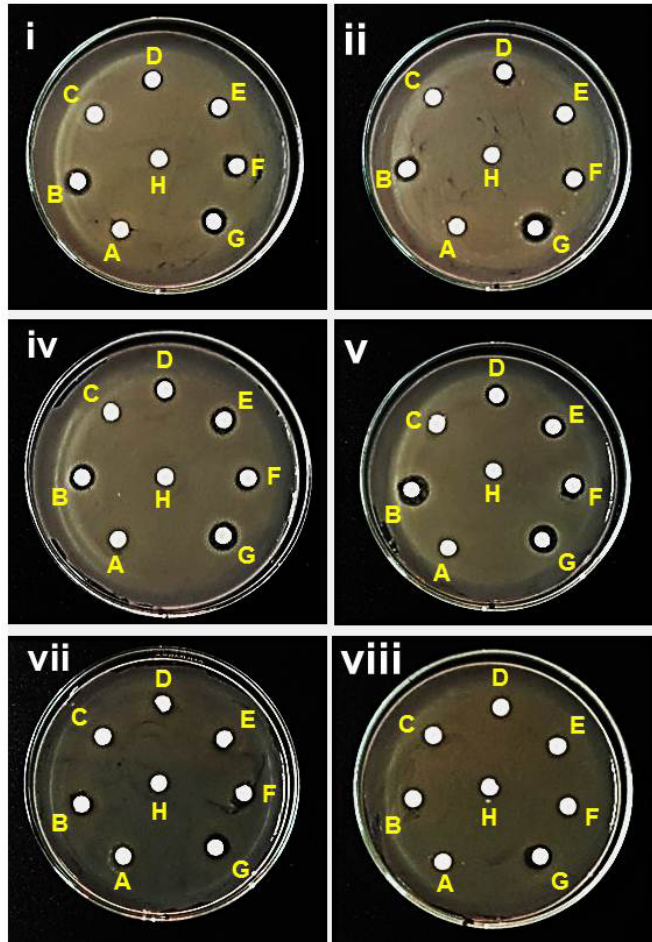
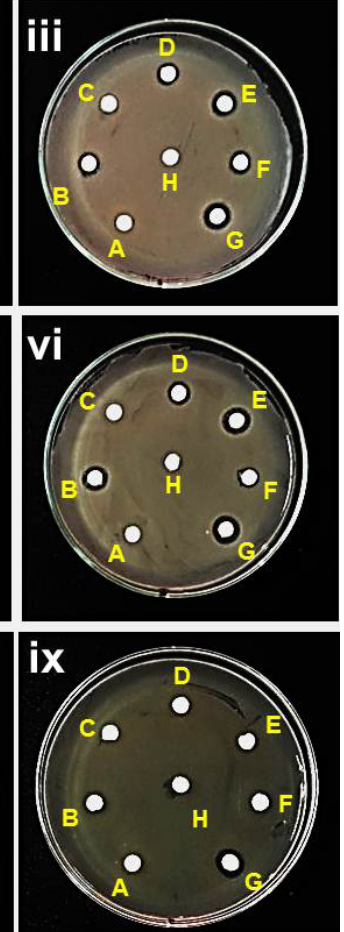

Figure 01: Antibacterial activity of sweet and sour orange juices. i, ii and iii: three replicated petri dishes grown with $E$. coli. iv, $v$ and vi: three replicated petri dishes grown with $S$. aureus. vii, viii and ix: three replicated petri dishes grown with methicillin resistant $S$. aureus. A to $\mathrm{F}$ are paper discs moistened with sweet orange juice. A: Arogya, B: Bibila sweet, C: MKD, D: Sisila, E: BAN, F: MT. G is the paper disc moistened with sour orange juice. $\mathrm{H}$ : control. The bacterial solution was streaked on to MHA plates and then respective paper discs were placed to examine the inhibition of bacterial growth around the disc. The ring shape zones around the disc marked the antibacterial activity and the thickness of the ring-shaped zone was measured and statistically analyzed (Table 01). 
Table 01: Antibacterial activity of the fruit juice of sweet orange cultivars and sour orange

\begin{tabular}{lccc}
\hline \multirow{2}{*}{ Sweet orange cultivar } & \multicolumn{3}{c}{ Mean diameter of the inhibition zone $(\mathrm{mm})$} \\
\cline { 2 - 4 } & $E$. coli & S. aureus & Methicillin Resistant S. aureus \\
\hline Arogya & $0.0 \mathrm{~d}$ & $0.0 \mathrm{~d}$ & $0.0 \mathrm{c}$ \\
Bibila sweet & $9.5 \mathrm{~b}$ & $10.2 \mathrm{a}$ & $6.3 \mathrm{~b}$ \\
MKD & $0.0 \mathrm{~d}$ & $0.0 \mathrm{~d}$ & $0.0 \mathrm{c}$ \\
Sisila & $8.2 \mathrm{c}$ & $7.8 \mathrm{c}$ & $0.0 \mathrm{c}$ \\
BAN & $8.0 \mathrm{c}$ & $9.7 \mathrm{~b}$ & $0.0 \mathrm{c}$ \\
MT & $8.5 \mathrm{c}$ & $7.8 \mathrm{c}$ & $0.0 \mathrm{c}$ \\
Sour orange & $10.8 \mathrm{a}$ & $10.8 \mathrm{a}$ & $9.3 \mathrm{a}$ \\
Control & $0.0 \mathrm{~d}$ & $0.0 \mathrm{~d}$ & $0.0 \mathrm{c}$ \\
\hline
\end{tabular}

* Means denoted by the same letters in a column are not significantly different at $P<0.05$

PCR amplification yielded approximately 440 bp band for all the sweet orange cultivars and sour orange (Figure 02). The DNA sequence alignment diagram (Figure 03) revealed that each DNA barcode is different from each other, making the cultivar or species is specific. Out of 442 bases aligned, 66 (15\%) bases represented single nucleotide polymorphisms (SNPs). Out of the 66 SNPs, only one INDEL position was observed between sour orange and sweet oranges, possibly contributing to the species divergence. Out of the 66 SNPs, a total of 55 SNPs were observed within sweet orange cultivars in which 51 were di-allelic and four were tri-allelic.

The dendrogram resulted from DNA sequence differences at $t r n H-p s b A$ region revealed clear separation of sour orange from the sweet oranges at $56 \%$ of the genetic similarity coefficient. At $68 \%$ of genetic similarity, all sweet orange cultivars were clustered together. $M T$ and Arogya were the genetically most similar sweet orange cultivars $(85 \%)$ (Figure 04$)$.

\section{DISCUSSION}

Citrus germplasm has a huge diversity in Sri Lanka. Although sweet orange cultivars have been characterized (Herath et al., 2014) and released (DOA, 2015), their true biochemical and economic potentials have not been characterized and utilized. Being a popular and one of the tastiest fruits, sweet orange processes a huge economic value as an industrial cash crop. Historically, many orange types were heavily utilized by indigenous medicinal practices and preparations (Seenivasan et al., 2006). The ethnobotanical knowledge base is immense regarding the use of Citrus in indigenous medical practices (Fonseka, 1902). In many countries these ethnobotanical knowledge bases were further explored and interesting bioactive properties of Citrus have been identified. Antioxidant activity (Abeysinghe et al., 2007) of sweet orange is well documented and attributed to many important phytochemicals present in Citrus fruits.

In the present study antibacterial activity of sweet orange cultivars and sour orange in Sri Lanka were evaluated against three model pathogenic bacterial species. In a similar study, the stem oil formulations from Citrus aurantifolia were tested with agar well diffusion method to identify the antibacterial effects against $S$. aureus, E. coli and Salmonella paratyphi and as the parameters of antibacterial activity, zone of inhibition and MIC were measured (Aibinu et al., 2007). Although the present study focused on fruit juice, Kabra et al., (2012) found that Citrus medica peels comprise antibacterial activity equivalent to $100 \mathrm{ppm}$ of streptomycin, a well-known antibiotic. The methanol extracts from peels of sweet and sour 
orange were proven to be inhibitory against Klebsiella pneumoniae and B. cereus (Madhuri, 2014). The Citrus extracts were historically reported to be effective against pathogenic bacteria living in the digestive tract. Twenty five percent concentrated lemon juice was found to be effective against enteric pathogens $E$. coli, S. paratyphi and Shigella sonnei (Bansode and Chavan, 2012). Similarly, antibacterial activity of lemon peel extracts (Dhanavade et al., 2011; Dimić et al., 2012) sweet orange leaf extracts (Ekwenye and Edeha, 2010), lemon extract (Hindi and Chabuck, 2013), mandarin (Khalil et al., 2003), and Citrus based natural extracts against E. coli (Nannapaneni et al., 2008) were reported. Even the dried Citrus materials were proven to possess significant antibacterial effects (Samarakoon et al., 2012). Grapefruit, lemon, sweet orange and lime were proven to be very successful against pathogens in gastrointestinal tract (Srividhya et al., 2013). Therefore the antibacterial activity of sweet and sour orange detected in the present study is in line with the findings of other studies and especially highlights the important of sweet orange. In the present study it was found that certain sweet orange cultivars do not possess antibacterial activities against the model pathogens, implying the presence of bioactive compounds in different sweet orange cultivars in variable quantities.
If sweet orange cultivars to be industrially used as a source of antibacterial compounds for extractions or value additions, the results of the present study would be very useful. In addition to the antibacterial activity, Citrus is often hailed as a genus with diverse medicinal values such as anticancerous properties. Lai et al., (2013) reported the flavonoids in Citrus peel can successfully suppress human prostrate xerographic tumors. They also suggested oral administration of peel extracts reduced the tumor weight by $57 \%$ to $100 \%$ and down regulate the expression of inflammatory enzymes. Lai et al, (2013) also suggested fruit and vegetable consumption as a nontoxic healing method of lethal cancers. The anticancerous activity of Citrus was further verified by work reported in Miller et al., (2004). Polymethoxyflavones in Citrus peels are related to inhibition of angiogenesis and other developmental activities of cancer (Wang et al., 2014). The alkaline extracts of Citrus reticulata were also found to be effective against pulmonary fibrosis (Zhou et al., 2013). Thus the antibacterial activity and other medicinal attributes such as anticancerous properties due to phytochemicals such as tannins and flavonoids clearly highlights the importance of characterizing sweet orange, sour orange and other Citrus germplasm further, for detailed medicinal properties.

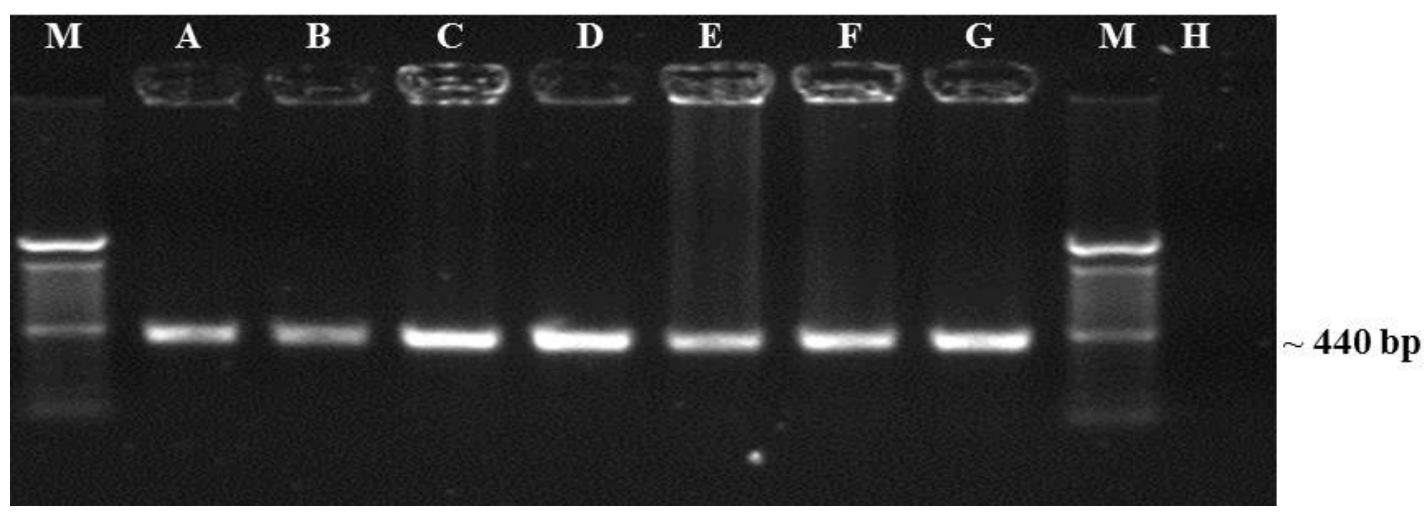

Figure 02: PCR amplification of $\operatorname{trn} H-p s b A$ region in tested sweet orange cultivars and sour orange. A: Arogya, B: Bibila sweet, C: MKD, D: Sisila, E: BAN, F: MT, G: Sour orange, H: Negative control. $M$ indicates the 100bp ladder (included twice). 


\section{Sour orange}

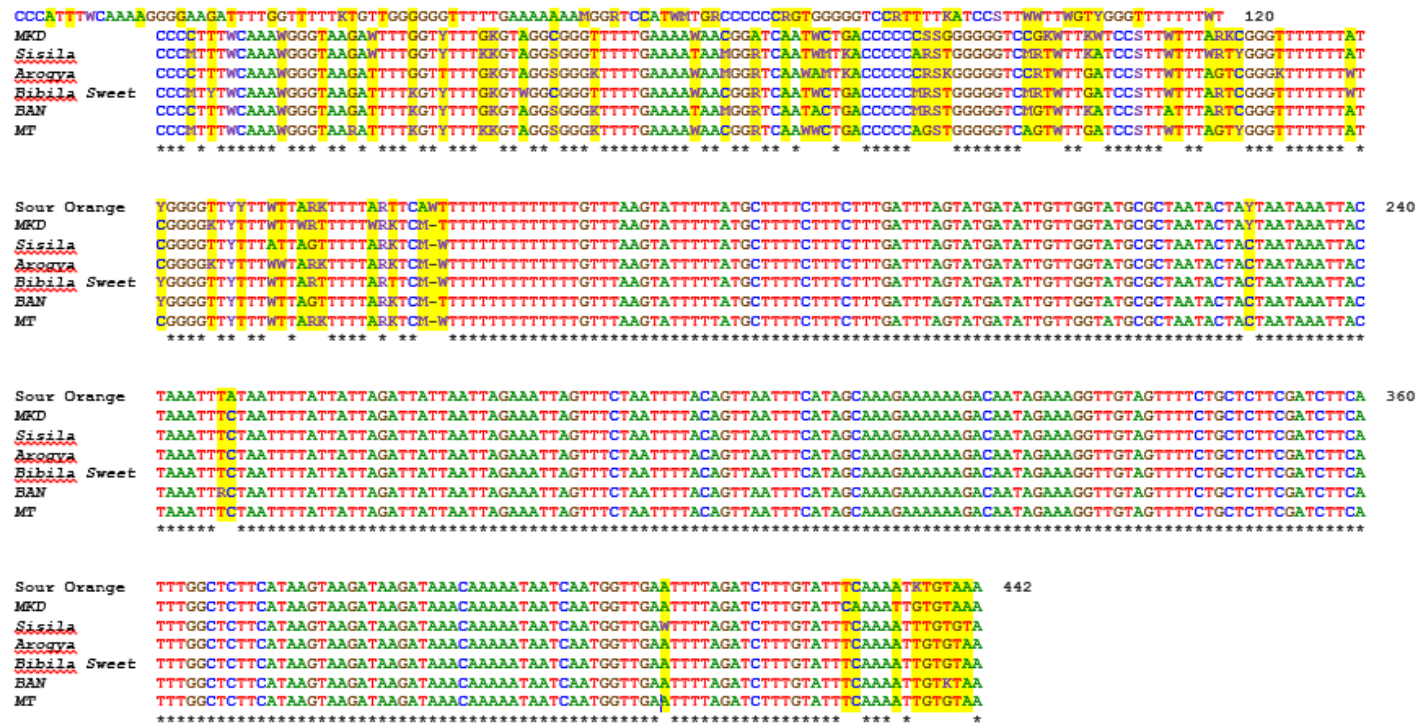

Figure 03: DNA sequence alignment diagram for $\operatorname{trn} H-p s b A$ region of the chloroplast genome of sweet orange cultivars and sour orange. The alignment was obtained by using clustal omega software. The symbol '*', indicates monomorphic nucleotides across the studied sweet orange cultivars and sour orange. Yellow shadings indicate the polymorphic nucleotides (i.e. SNPs). The sweet orange cultivar names or sour orange are indicated in the left and number of bases depicted in each line is marked by the number shown at the top right of each section. The DNA sequence differences shown in this illustration were used to draw the genetic dissimilarity diagram (i.e. dendrogram) shown in Figure 04.

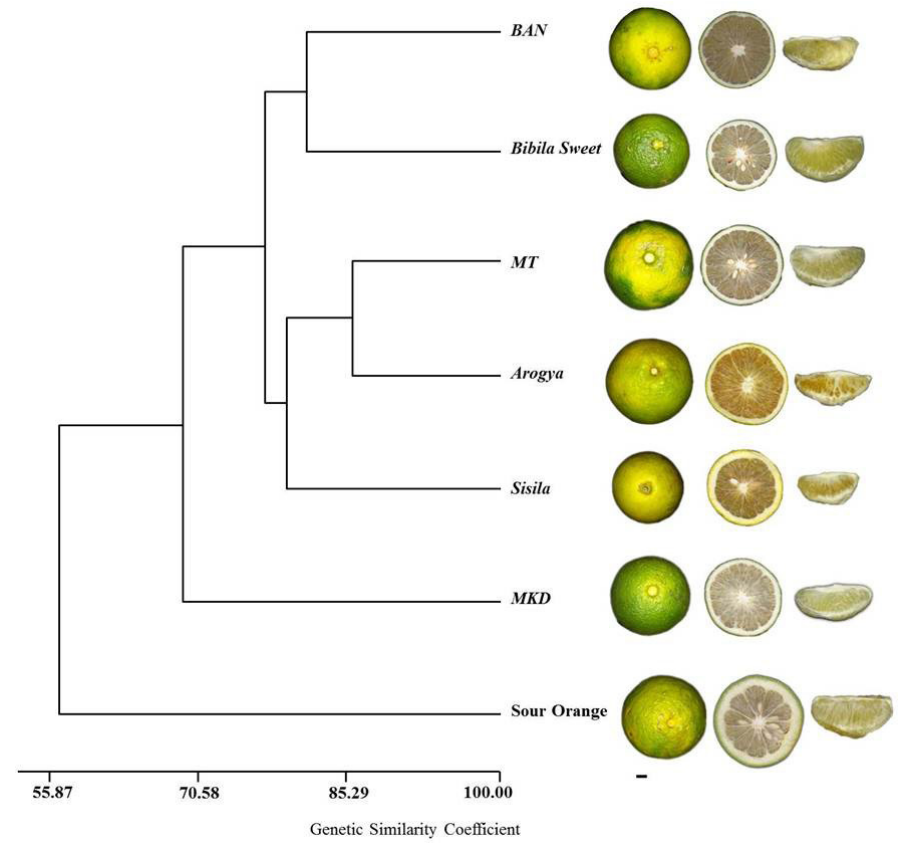

Figure 04: Genetic similarity structure of tested sweet orange cultivars and sour orange based on the genomic DNA sequence of $\operatorname{trnH}-p s b A$ region in the chloroplast genome. The SNPs depicted in sequence alignment diagram (Figure 03 ) were used to calculate the pair wise similarity of sweet orange cultivars and sour orange. A complete fruit, a cross section and a carpel of each cultivar are shown alongside. Note that sour orange is an out-group indicating the highest molecular divergence from sweet orange which is a different species. The scale bar is only relevant to fruit related images and represent $1 \mathrm{~cm}$ in actual size. 
The sweet orange cultivars in Sri Lanka primarily consist of selections and could be traced back to the mother trees that were originally selected. Therefore, within cultivar genetic diversity is not available for these released sweet orange cultivars. In that context, DNA barcoding could be suggested to authenticate the different sweet orange cultivars and sour orange. The authentication of natural health products was reported to be essential and the required PCR based DNA sequencing primer pairs are summarized for plant and animal product DNA barcoding (reviewed in Wallace et al., 2012). SNPs markers and DNA barcoding based on the ITS region was employed to genetically identify Citrus species (Wang et al., 2012) and other medicinal plants (Techen et al., 2014). The present study could be used as an ideal model to characterize the antibacterial or any other important medicinal properties and then to authenticate the tested species and cultivars using DNA barcoding to use them in future large scale industrial applications.

\section{CONCLUSION}

The sweet orange cultivars Arogya and MKD do not have any antibacterial activity. The sweet orange cultivars Sisila, BAN and MT only have antibacterial activity against E.coli and S. aureus. Sweet orange cultivar Bibila sweet and sour orange have significantly higher antibacterial activity against $E$. coli, $S$. aureus and MRSA. Sweet orange cultivar Bibila sweet can be presented as a better variety with higher antibacterial activity in the fruit juice. The trnH-psbA based DNA barcoding resulted unique DNA sequence based identifiers for all the sweet orange cultivars and sour orange tested in the study.

\section{REFERENCES}

Abeysinghe, D.C., Li, X., Sun, C., Zhang, W., Zhou, C. and Chen, K. (2007). Bioactive compounds and antioxidant capacities in different edible tissues of Citrus fruit of four species, Food Chemistry. 104(4): 1338-1344.

Aibinu, I., Adenipekun, T., Adelowotan, T., Ogunsanya, T. and Odugbemi, T. (2007). Evaluation of the antimicrobial properties of different parts of Citrus aurantifolia (Lime fruit) as used locally, African Journal of Traditional, Complementary and Alternative Medicine. 4(2): 185190.

Al-ani, W., Al-Halem, S.M. and Tawfik, N.O. (2010). Evaluation of the antibacterial activity of Citrus juices: An in vitro study, Al-Rafidain Dental Journal. 10(2): 376-382.

Asahina, H., Shinozaki, J., Masuda, K., Morimitsu, Y. and Satake, M. (2010). Identification of medicinal Dendrobium species by phylogenetic analyses using mat $K$ and $r b c L$ sequences, Journal of Natural Medicines. 64: 133-138.

Bansode, D.S. and Chavan, M.D. (2012). Studies on antimicrobial activity and phytochemical analysis of Citrus fruit juices against selected enteric pathogens, International Research Journal of Pharmacy. 3(11): 122-126.

Chao, Z., Zeng, W., Liao, J., Liu, L., Liang, Z. and Li, X. (2014). DNA barcoding Chinese medicinal Bupleurum, Phytomedicine. 21(13): 1767-1773. 
Chase, M.W., Salamin, N., Wilkinson, M., Dunwell, J.M., Kesanakurthi, R.P., Haidar, N. and Savolainen, V. (2005). Land plants and DNA barcodes: short-term and long-term goals, Philosophical Transactions of the Royal Society of London Series B, Biological Sciences. 360: 1889-1895.

Dhanavade, M.J., Jalkute, C.B., Ghosh, J.S. and Sonawane, K.D. (2011). Study antimicrobial activity of lemon (Citrus lemon L.) peel extract, British Journal of Pharmacology and Toxicology. 2(3): 119-122.

Dimić, G.R., Kocić-Tanackova, S.D., Jovanovb, O.O., Cvetkovića, D.D., Markova, S.L. and Velićanskia, A.S. (2012). Antibacterial activity of lemon, caraway and basil extracts on listeria spp, Acta Periodica Technologica. 43(1): 239-246.

Department of Agriculture Sri Lanka DOA (2015). http://www.agridept.gov.lk/index.php/en/croprecommendations/1086. 15.07. 2015.

Ekwenye, U.N. and Edeha, O.V. (2010). The antibacterial activity of crude leaf extract of Citrus sinensis (sweet orange), International Journal of Pharma and Bio Sciences. 1(4): 743-750.

Fonseka, D.K. (1902). Oushadha Mukthaharaya. $2^{\text {nd }}$ Edition. Colombo. Sudarshana Printers. Pp. 19.

Harborne, J.B. (1994). Indian Medicinal Plants. A Compendium of 500 Species. Vol.1; (Warrier, P.K., Nambiar, V.P.K. and Ramankutty, C. Eds.), Journal of Pharmacy and Pharmacology. 46: 935.

Herath, H.M.P.D., Kasthuriarachchi, V.D.W., Chamikara, M.D.M., Ishan, M., Somachandra, K.P., Dissanayake, N.B.U., Iroshani, R.G.S., Heenkenda, H.M.S., Samaraweera, P. and Sooriyapathirana, S.D.S.S. (2014). Morphological characterization and consumer acceptance of sweet orange cultivars vis-à-vis sour orange in Sri Lanka, Rajarata University Journal. 2: $50-57$.

Hindi, N.K.K. and Chabuck, Z.A.G. (2013). Antimicrobial activity of different aqueous lemon extracts, Journal of Applied Pharmaceutical Science. 3(6): 74-78.

Hirota, R., Roger, N.N., Nakamura, H., Song, H.S., Sawamura, M. and Suganuma, N. (2010). Anti-inflammatory effects of limonene from yuzu (Citrus junos Tanaka) essential oil on eosinophils, Journal of Food Science. 75(3): 87-92.

Kabra, A.O., Bairagi, G.B., Mahamuni, A.S. and Wanare, R.S. (2012). In vitro antimicrobial activity and phytochemical analysis of the peels of Citrus medica L, International Journal of Research in Pharmaceutical and Biomedical Sciences. 3(1): 34-37.

Khalil, A.T., Maatooqa, G.T. and Sayeda, K.A.E. (2003). Limonoids from Citrus reticulata, Journal of Biosciences. 58(4): 165-170.

Lai, C.S., Li, S., Miyauchi, Y., Suzawa, M., Ho, C.T. and Pan, M.H. (2013). Potent anti-cancer effects of citrus peel flavonoids in human prostate xenograft tumors, Food Functioning. 4(6): 944-951. 
Liu, Z., Zeng, X., Yang, D., Ren, G., Chu, G., Yuan, Z., Luo, K., Xiao, P. and Chen, S. (2012). Identification of medicinal vines by ITS2 using complementary discrimination methods, Journal of Ethnopharmacology. 141: 242-249.

Madhuri, S., Hegde, A.U., Srilakshmi, N.S. and Kekuda, P.T.R. (2014). Antimicrobial activity of Citrus sinensis and Citrus aurantium peel extracts, Journal of pharmaceutical and Scientific Innovation. 3(4): 366-368.

Miller, E.G., Porter, J.L., Binnie, W.H., Guo, I.Y. and Hasegawa, S. (2004). Further studies on the anticancer activity of Citrus limonoids, Journal of Agricultural and Food Chemistry. 52(15): 4908-4920.

Nannapaneni, R., Muthaiyan, A., Crandall, P.G., Johnson, M.G., O’Bryan, C.A., Chalova, V.I., Callaway, T.R., Carroll, J.A., Arthington, J.D., Nisbet, D.J. and Ricke, S.C. (2008). Antimicrobial activity of commercial Citrus-based natural extracts against Escherichia coli O157:H7 isolates and mutant strains, Foodborne Pathogenic Disease. 5(5): 695-704.

Okwu, D.E. and Emenike, I.N. (2006). Evaluation of the phytonutrients and vitamins content of Citrus fruits. International Journal of Molecular Medicine and Advance Sciences. 2: 1-6.

Pang, X., Liu, C., Shi, L., Liu, R., Liang, D., Li, H., Cherny, S.S., and Chen, S. (2012). Utility of the trnH-psbA intergenic spacer region and its combinations as plant DNA barcodes: A Meta-Analysis, Public Library of Science one. 7(11): e48833.

Samarakoon, K., Senevirathne, M., Lee, W., Kim, Y., Kim, J., Oh, M. and Jeon, Y. (2012). Antibacterial effect of citrus press-cakes dried by high speed and far-infrared radiation drying methods, Nutrition Research and Practice. 6(3): 187-194.

Seenivasan, P., Manickkam J. and Savarimuthu, I. (2006). In vitro antibacterial activity of some plant essential oils, BioMed Central Complementary and Alternative Medicine. 6: 39.

Srividhya, M., Ramanathan, K. and Krishnanand, N. (2013). Efficacy of Citrus fruit peel extracts against pathogens causing gastrointestinal disorders, International Journal of Pharmacy and Pharmaceutical Sciences. 5(4): 160-163.

Techen, N., Parveen, I., Pan, Z. and Khan, I.A. (2014). DNA barcoding of medicinal plant material for identification, Current Opinion in Biotechnology. 25: 103-110.

Theodoridis, S., Stefanaki, A., Tezcan, M., Aki, C., Kokkini, S. and Vlachonasios, K.E. (2012). DNA barcoding in native plants of the Labiatae (Lamiaceae) family from Chios Island (Greece) and the adjacent Cesme-Karaburun Peninsula (Turkey), Molecular Ecology Resources. 12: 620-633.

Tian-Shung, W., Chang-Shenga, K. and Furukawa, H. (1983). Acridone alkaloids and a coumarin from Citrus grandis, Phytochemistry. 22(6): 1493-1497.

Wallace, L.J., Boilard, S.M.A.L., Eagle, S.H.C., Spall, J.L., Shokralla, S. and Hajibabaei, M. (2012). DNA barcodes for everyday life: Routine authentication of Natural Health Products, Food Research International. 49: 446-452. 
Wang, H., Kim, M.K., Kim, Y.J., Lee, H.N., Jin, H., Chen, J. and Yang, D.C. (2012). Molecular authentication of the oriental medicines Pericarpium citri reticulatae and Citri unshius pericarpium using SNP markers, Gene. 494: 92-95.

Wang, L., Wang, J., Fang, L., Zheng, Z., Zhi, D., Wang, S., Li, S., Ho, C. and Zhao1, H. (2014). Anticancer activities of Citrus peel polymethoxyflavones related to angiogenesis and others, BioMed Research. 2014: 1-10.

$\mathrm{Xu}$, C.J., Fraser, P.D., Wang, W.J. and Bramley, P.M. (2006). Differences in the carotenoid content of ordinary Citrus and lycopene-accumulating mutants, Journal of Agriculture food Chemistry. 54(15): 5474-5555.

Xu, Q., Chen, L.L., Ruan, X., Chen, D., Zhu, A., Chen, C., Bertrand, D., Jiao, W.B., Hao, BH., Lyon, M.P., Chen, J., Gao, S., Xing, F., Lan, H., Chang, J.W., Ge, X., Lei, Y., Hu, Q., Miao, Y., Wang, L., Xiao, S., Biswas, M.K., Zeng, W., Guo, F., Cao, H., Yang, X., Xu, X.W., Cheng, Y.J., Xu, J., Liu, J.H., Luo, O.J., Tang, Z., Guo, W.W., Kuang, H., Zhang, H.Y., Roose, M.L., Nagarajan, N., Deng, X.X. and Ruan, Y. (2013). The draft genome of sweet orange (Citrus sinensis), Nature Genetics. 45(1): 59-66.

Youseif, S.H., El-Halwagi, A., Sayed, H.A. and El-Itriby, H.A. (2014). Chemical analyses, antibacterial activity and genetic diversity assessment of some Egyptian Citrus spp. cultivars, African journal of Biotechnology. 13: 2626-2636.

Zhou, X.M., Wen, G.Y., Zhao, Y., Liu, Y.M. and Li, J.X. (2013). Inhibitory effects of alkaline extract of Citrus reticulata on pulmonary fibrosis, Journal of Ethnopharmacology. 146(1): $372-140$.

Zuo, Y., Chen, Z., Kondo, K., Funamoto, T., Wen, J. and Zhou, S. (2011). DNA barcoding of Panax species, Planta Medica. 77: 182-187. 